\title{
SAND94-2163C \\ CORE DAMAGE FREQUENCY OBSERVATIONS AND INSIGHTS OF LWRS BASED ON THE IPES
}

\author{
S. E. Dingman', M. T. Drouin ${ }^{2}$, A. L. Camp ${ }^{1}$, A. Kolaczkowski ${ }^{3}$, J. Darby4, J. L. LaChance ${ }^{3}$, J. Yakle ${ }^{3}$ \\ ${ }^{1}$ Sandia National Laboratories \\ ${ }^{2}$ U.S. Nuclear Regulatory Commission \\ ${ }^{3}$ Science Applications International, Corp. \\ ${ }^{4}$ Science and Engineering Associates
}

\begin{abstract}
Seventy-eight plants are expected to submit Individual Plant Examinations (IPEs) for severe accident vulnerabilities to the U.S. Nuclear Regulatory Commission (NRC). The majority of the plants have elected to perform full Level 1 probabilistic risk assessments (PRAs) to meet the intent of the IPEs. Because of this, it is possible to compare the results from the IPE submittals to determine general observations and "lessons learned" from the IPEs. The IPE Insights Program is performing this evaluation, and preliminary results are presented in this paper. The core damage frequency and core damage sequences are identified and compared for pressurized water reactors and boiling water reactors. Examination of the results indicates that variations among plant results are due to a combination of actual plant design/operational features and analysis approaches. The findings are consistent with previous NRC studies, such as WASH-1400 and NUREG-1150.
\end{abstract}

\section{BACKGROUND AND OBJECTIVES}

On August 8, 1985, the Nuclear Regulatory Commission (NRC) issued a Policy Statement on Severe Accidents regarding Future Designs and Existing Plants (50 FR 32138) that introduced the Commission's plan to address severe accident issues for existing commercial nuclear power plants. In this Policy Statement, the Commission addressed its plan to formulate an approach for a systematic safety examination of existing plants to study particular accident vulnerabilities and desirable cost-effective changes so as to ensure that there is no undue risk to public health and safety. To implement this plan, NRC issued Generic Letter 88-20, in November 1988, requesting all licensees to perform an Individual Plant Examination (IPE) to identify any plant-specific vulnerabilities to severe accidents and to report the results to the Commission. The purpose and scope of the IPE effort includes examination of internal events, including those initiated by internal flooding, occurring at full power. In concert with the objectives of the above NRC Policy Statement on Severe Accidents, a memorandum from the Executive Director of Operations to the Office of Nuclear Regulatory Research in NRC on May 12, 1993, recommended that NRC should publish a World-Class document highlighting the significant safety insights resulting from this program and showing how the safety of reactors has been improved by the IPE initiative.

Seventy-eight IPEs are expected to be submitted to the NRC staff in response to the Generic Letter. The NRC staff is reviewing the IPEs to determine if the licensee met the intent of the Generic Letter. A staff evaluation report (SER) documenting the staff's response is prepared at the completion of each review.

The Generic Letter did not require the licensees to perform a full Level 1 probabilistic risk assessment (PRA). However, the majority of the licensees have elected to do so. Because of this, it is possible to compare results from the IPE submittals to determine general observations and "lessons learned" from the IPE initiative. The IPE Insights Program was initiated to document such safety insights. The emphasis of the program is to search for any potential generic significance arising from plant features, e.g., system

* This work was supported by the U.S. Nuclear Regulatory Commission and was performed at Sandia National Laboratories, which is operated for the U.S. Department of Energy under Contract Number DE-AC04-94AL85000. 


\section{DISCLAIMER}

Portions of this document may be illegible in electronic image products. Images are produced from the best available original document. 
design, plant operation, for different classes of plants. The program is also quantitatively assessing the impact of the proposed plant changes and modifications (identified by the licensees from their IPE program) on core damage frequency (CDF) and containment performance. The IPE Insights Program is thus documenting the significant safety insights relative to the CDF and containment performance results. This paper is limited to the CDF findings from the IPEs.

As a summary, Figure 1 shows the key points in the evolution of the IPE Insights Program. The figure also shows the interrelationships between this program and other NRC efforts.

The objective of the IPE Insights program is to document the significant safety insights relative to CDF for the different reactor and containment types and plant designs as indicated in the IPEs. The major insights to be gained include:

- What is the nuclear power industry's own judgment of the CDF risk from operating nuclear power plants?

- How does the risk compare among and within various plant groups?

- How does the risk compare against previous risk estimates and the safety goals?

- What is driving the CDF risk?

- What are the important (significant and nonsignificant) designs, operational features, etc. that increase or decrease risk?

- How important is the role of the plant operators in determining risk?

- Are some of the findings (differences and similarities) artifacts of the methodology, assumptions, etc?

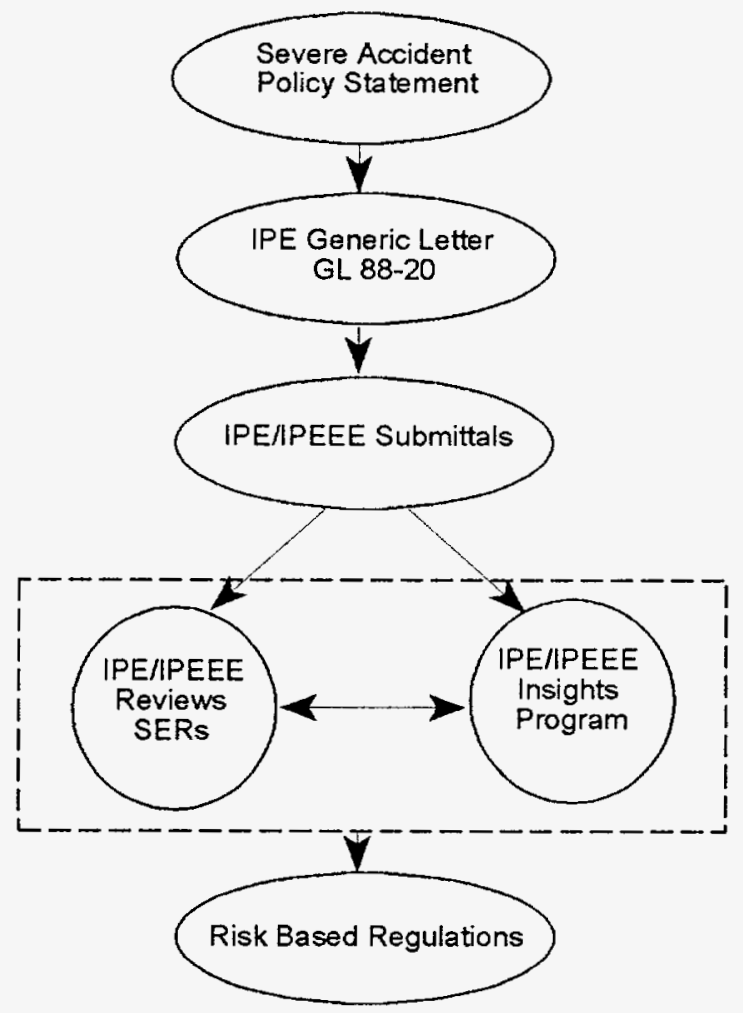

Figure 1. Role of IPEs in NRC Severe Accident Policy 
- What is the impact of plant improvements resulting from the IPEs?

- Has the IPE process had an impact on the safety of plants?

- How much variation is there among the plant IPE results resulting from implementation of plant improvements?

- Are there any "generic" improvements that have significantly affected the plant CDFs, or are the plant improvements plant specific?

- How do the IPE models compare?

- Is there any consistency or standardization?

- What are the potential viable applications?

\section{ANALYSIS OVERVIEW}

To accomplish the program objectives, the IPE/IPEEE Insights Program is composed of four key tasks, as shown in Figure 2:

1. Develop insights related to core damage frequency and its drivers;

2. Develop insights related to containment performance;

3. Examine the impact of plant improvements that were noted in the IPEs; and

4. Address and compare the modeling approaches used in the IPEs, and how those approaches can affect the potential viable applications of the IPEs.

\section{IPE/IPEEE INSIGHTS PROGRAM}

1 CDF Insights
Compare Modeling, Plant Features, Results
Develop Insights

Figure 2. Tasks in IPE/IPEEE Insights Program 
This paper presents the approaches being used in and preliminary results from the IPE Insights Program for the first of the four tasks. The approach used to perform the task is summarized in the next section of this paper, followed by a summary of the IPE CDF results, CDF drivers, and preliminary CDF-related insights. The IPE treatment of human actions is discussed in another paper at this conference*.

This program is developing insights related to the core damage frequency as reported in the IPE submittals. The correctness of the IPE modeling is not addressed here because it is being considered in the NRC staff reviews that are documented in SERs. The insights are limited to internal initiators and internal flooding events at full power. Other modes of operation, such as shutdown, are not considered in the IPE initiative. Some licensees have reported additional external events results, but they are not reviewed in the scope of this work. However, the IPE/PEEE Insights Program will examine external events implications at a later time.

The IPEs reflect plant conditions at a "snapshot" in time. The licensees have all indicated that they are planning to make improvements to either plant systems/configurations or operating conditions. These are the plant improvements being examined for task 3. In some cases, the IPEs have taken credit for these changes, while in other cases they have not. This variability introduces nonuniformity when comparing the reported plant results, and the IPEs do not provide adequate information to fully account for these differences (i.e., to "normalize" the results). The insights regarding CDF (for task 1) do not attempt to "normalize" the results to account for this concern.

\section{TECHNICAL APPROACH}

The approach used to derive safety insights from the IPE submittals regarding core damage frequency results is summarized in this section. A three-step process was used. First, the results from the IPEs were identified and categorized. Second, support information that was believed to be important for explaining commonalities and differences in results among the IPEs was identified. This included information on plant characteristics, the methods and data used in the IPEs, and the assumptions that were made in the analysis. Third, the information obtained in the first and second steps was evaluated and assessed so that global perspectives on the IPE results could be gained.

Developing these findings involved a considerable effort in comparing plant results, design information, and analysis information. To facilitate this, NRC's IPE database, which was developed to store information from the licensee's IPEs, was used. This information includes plant design, CDF and containment performance information. It was also necessary to gather supplementary information from the IPEs so that commonalities and differences in IPE results could be explained. The desired information was not always contained in the submittals, which limited the insights that could be drawn.

The plants were categorized in various ways in order to gain insights from the IPEs regarding commonalities and differences within and across logical groupings of plants. The first grouping is a breakdown of the plants in terms of whether a plant is a Boiling Water Reactor (BWR) or a Pressurized Water Reactor (PWR). The BWRs are further grouped by major model and containment type: BWRs 1, 2, or 3 with isolation condensers and Mark I containments as a group; BWRs 3 and 4 with Reactor Core Isolation Cooling (RCIC) and Mark I containments as a group (a few of the BWRs 3 and 4 with RCIC have Mark II containments, and are included in this group); BWR 5s with Mark II containments; and finally, BWR 6s with Mark III containments. For the PWRs, the first grouping is by vendor (i.e., Westinghouse,

* J. A. Forester, "Human Event Observations in the Individual Plant Examinations." 


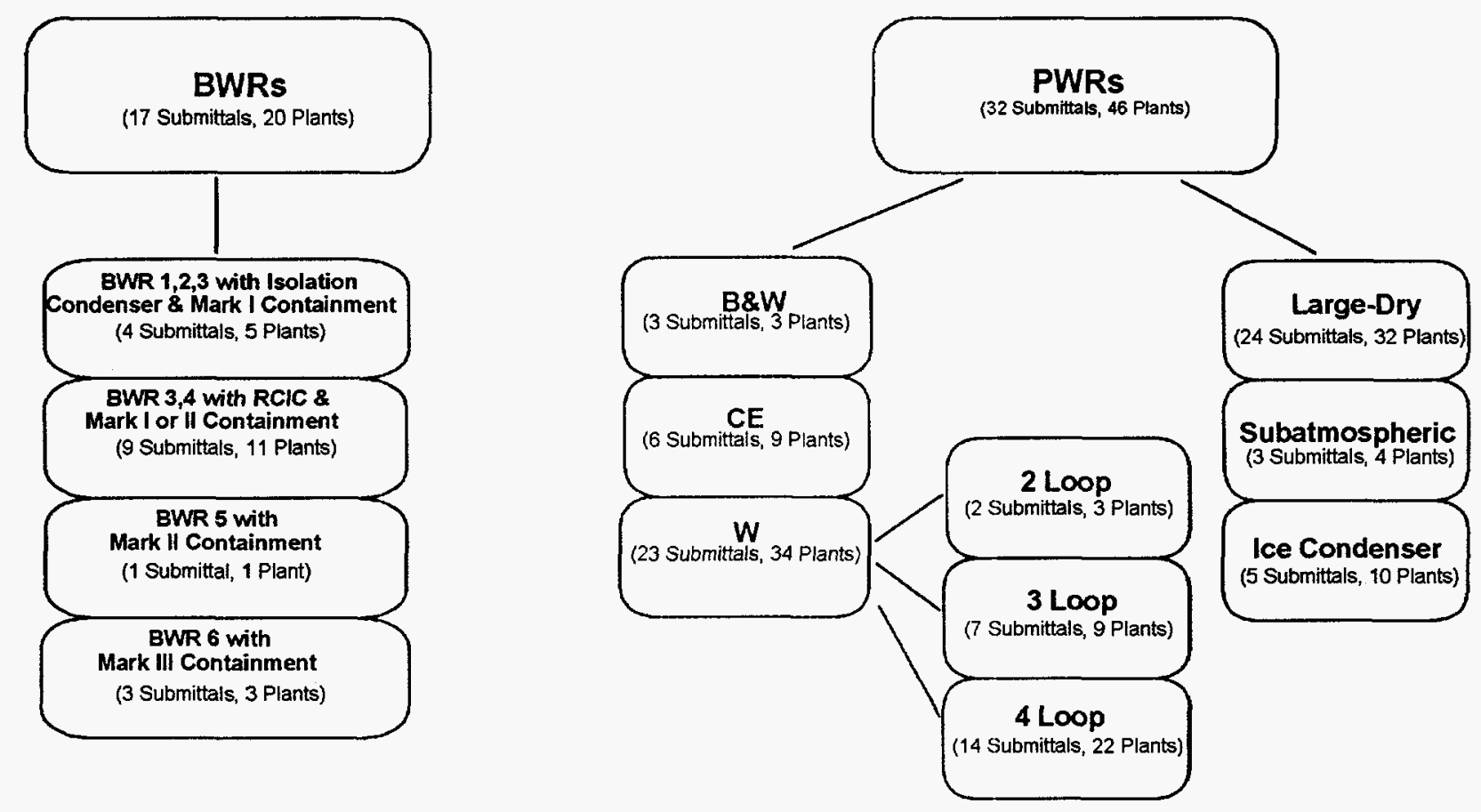

Figure 3. Plant groupings

Combustion Engineering, or Babcock and Wilcox). The Westinghouse plants are further broken down into groups based on the number of coolant loops the plant has (i.e., 2, 3, or 4 loops). Additionally, a separate grouping of all PWRs is made by containment type (i.e., Large Dry, Ice Condenser, or Subatmospheric type containment). These various plant groupings are summarized in Figure 3.

\section{Step 1: Identification and Categorization of IPE CDF Results}

For the first step, identifying and categorizing the IPE CDF results, a tiered approach was followed. The results were first examined at a high level, followed by a systematic progression to more detailed levels. The CDF results were examined first, followed by sequence level results, and then the dominant contributors to those sequences.

\section{Tier 1 - Plant Core Damage Frequency}

For a Level 1 PRA, the outcome that provides an overall comparable insight into the safety of a nuclear power plant is the plant CDF. As a result, Tier 1 is a comparison of the CDF (either mean or point estimate, whichever was provided in the submittal) across the plants and subgroups of plants.

The first level of insights comes from a comparison of the CDF for each of the plants to be considered in this program. The result of this comparison was summarized by plotting the CDF mean, median, and the individual estimates for the entire population of plants reviewed in this program. This comparison provides insights into the spread and weighting of the CDF values representing all the reviewed IPE submittals. Next, the collective set of CDF values within each of the groups identified above was summarized by 
plotting the CDF mean and the individual estimates for all plants identified as belonging within each group (e.g., all BWRs, all BWR 5s, etc.). The results were then compared to determine the variations that exist among and within the plant groups.

\section{Tier 2 - Accident Sequences}

The general insights gained from comparing the CDFs for the various plants and groups of plants were further enhanced by examining the individual accident sequences driving the overall CDF for each plant. It must be recognized that there can be a variety of accident sequences that can potentially dominate the CDF and these sequences can be plant specific. Also, the way an accident sequence is defined can vary from IPE to IPE. Typical approaches for defining accident sequences include the following:

- functional [in terms of failed functions resulting in core damage, such as reactor coolant system (RCS) inventory control or heat removal], or

- $\quad$ systemic (in terms of failed systems that lead to core damage), or

- a combination of these two.

Hence, for this program, a standard set of sequence definitions needed to be derived. Once the sequence definitions were derived, all of the IPE-identified dominant accident sequences could be classified into these "standard" sequences for proper comparison. It would be desirable to have sequence descriptions that included summary descriptors such as the type of initiator, timing of core damage, etc. However, this information was not reported in many of the IPE submittals, while other submittals contained such a detailed level of sequence reporting that a very large number of sequences were needed to represent the bulk of the CDF. Because of these limitations, the comparisons among IPEs were based on a higher level sequence description. These summary sequences are listed in Table 1.

The sequence results were compared for the plant groups defined in Figure 3. For each plant group and for each sequence group identified, both the sequence CDF and the percent contribution to the total CDF were reported. The information was summarized by plotting the mean and the individual estimates for all plants within a particular group. The results from this stage of the program allowed insights to be gained regarding how the dominant accident sequence types and their relative contributions vary (or are similar) within and across plant groups.

Table 1. Summary Sequences

SBO - Station Blackout

ATWS - Anticipated Transient Without Scram

DHR - Transients with Loss of Containment Heat Removal (BWRs only)

$T$ - Other Transients

LOCA - Loss-of-Coolant Accidents

FLD - Internal Flood Initiators

R - Vessel Rupture

$V$ - Interfacing Systems LOCA

SGTR - Steam Generator Tube Rupture (PWRs only) 


\section{Tier 3 - Dominant Contributors}

After the dominant accident sequences were examined for each of the plant groups, the dominant contributors to the most significant sequence types were examined to enhance the insights gained thus far. As with the sequences, variability among the IPEs on how dominant contributors are identified had to be addressed. For example, some submittals only identify dominant contributors to the total CDF, while other submittals identify dominant contributors for each of the accident sequences. In addition, some submittals report contributors at the system level while other submittals report contributors at the component level.

The dominant contributors were identified for the most significant summary accident sequences. When sufficient detail was provided, the form of the identification was specific (i.e., the system in which the failure occurred was identified; the failure was identified as a component failure or a human error; and the failure mode was identified).

For the most significant summary sequences and for each plant group, a listing of each of the dominant contributors that were identified was provided. This listing identified which dominant contributors were contributing to which accident sequences and also which plant groups. This allowed the determination of the relative level of commonality among the contributors within each plant group that make the plants vulnerable to this type of sequence.

\section{Step 2: Identification and Categorization of IPE Methods, Data, Assumptions}

The second step in the process of deriving safety insights consisted of identifying and categorizing the methods, data, and assumptions used in the various IPEs. This information was collected so that it could be used to determine possible reasons for similarities and differences of IPE results (which were identified through step one).

The necessary information included both actual plant characteristics and the representation of the plant in the IPE analyses. This information provided some of the issues and potential factors (differences in design, methodology and assumptions) necessary for drawing generic insights from the IPE results, and determining the impact of actual plant characteristics versus analyses characteristics. This information was not available for all cases, which limited the ability to fully explain differences in results.

Similarly, to determine the impact of analysis assumptions on the results, information was needed regarding methods used and assumptions made in areas that could significantly impact the results. Examples include the method used in performing the Human Reliability Analysis (HRA) and assumptions regarding continued operation following battery depletion.

\section{Step 3: Examination for Generic Implication}

In the first two steps of this process, an attempt was made to simply summarize, categorize, and compare the IPE results. The third step was to attempt to identify the plant commonalities and differences that cause the results to be as they are.

This examination was focused on selected sequences and issues, rather than on a comprehensive evaluation of all possibilities. To identify which sequences and issues to address, the results from the CDF, accident sequences, and dominant contributors were first reviewed, and based on this review, "differences of interest" were identified. This predominantly involved differences in dominant sequence frequencies among various plant groups as well as the spread in frequencies within individual plant groups. If a large variation in sequence frequencies was noted among or within plant groups, the reasons for the variation were explored. In addition, the sequences with the greatest contribution to CDF for the 
particular plant groups were investigated to attempt to determine the factors that most heavily influenced the results.

Reasons for the "differences of interest" were explored by correlating the results with the factors that should have the greatest impact on the results. These factors were identified by examining the dominant contributors to the sequences. The sequence frequencies were then plotted against the factors of interest, and these plots were examined to determine whether any single factor had a large impact on the results. In some cases, outliers were also examined to determine if there were specific factors that caused them to vary from the other plants in the group. Some preliminary results are given in the next section of this paper.

\section{SUMMARY OF IPE RESULTS AND PRELIMINARY INSIGHTS}

Figure 4 shows the CDF for the 49 IPEs (representing 66 plants because of multiunit sites) that have been examined to date for this program. Individual plant results are shown by the diamonds in the plot, with the results grouped for the 66 light water reactor (LWR) plants, the 46 PWR plants and the 20 BWR plants. The highest and lowest CDFs reported are approximately $3 E-4$ and $2 E-6$, representing a factor of about 150 between the highest and lowest values. The BWRs generally have lower CDFs than the PWRs, with the mean CDF for the PWRs being about a factor of four higher than the mean CDF for the BWRs. However, the spread in the results is large enough that many of the individual PWR CDFs are lower than individual BWR CDFs.

The CDFs were also examined for the various plant groups described above. The differences in mean CDFs among plant group were less than the variations in CDF among the individual plant groups.

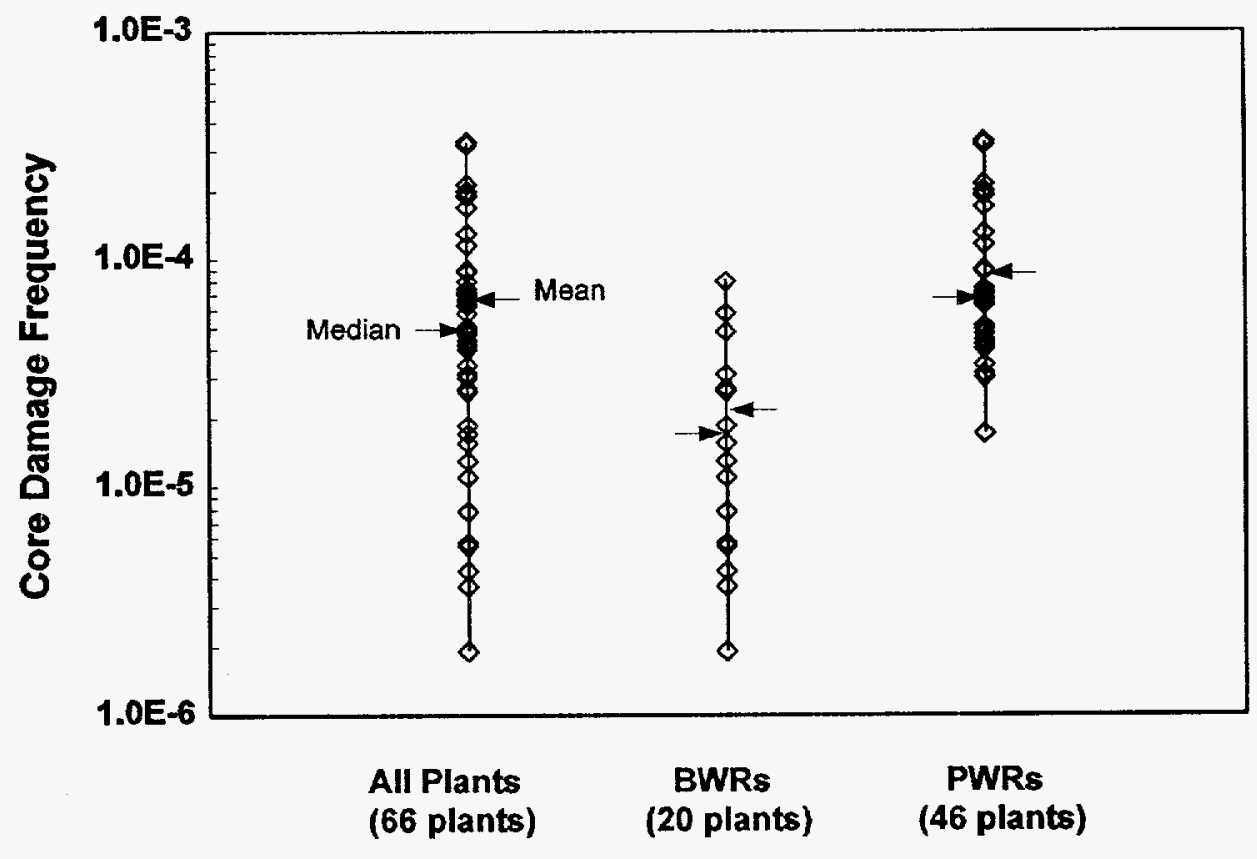

Figure 4 Comparison of BWR and PWR CDF Results for Internal Events 
The results for the summary sequences are shown in Figures 5 and 6 for the PWRs and BWRs, respectively. Each figure contains a plot of the individual plant sequence CDFs and a plot of the percent contribution of the sequences to the plant CDFs. The sequence contributions were obtained from summary information in the IPEs. In most cases, the IPE results were reported in a manner that allowed us to determine contributions for the summary sequences, but in some cases, it was not possible to determine the contribution for a particular summary sequence. We included such plants in the comparisons, but only for the information we were able to obtain from the submittal. As a result, the number of plants represented in the various summary sequences is not uniform.

The dominant sequences for PWRs are SBO, ATWS, T, LOCA and FLD. The steam generator tube rupture, bypass and vessel rupture contributions are much smaller. As shown in Figure 5, no single sequence appears as overwhelmingly dominant for the bulk of PWRs, indicating that the IPEs have not identified any generic problem that would dominate the risk for PWRs. The spread in plant results, both in terms of frequency and fractional contribution, is fairly large within all of the sequences, and is larger than the variation in means among the summary sequences. The spread in the CDF is about two orders of magnitude for SBO, T, and LOCA, with means in the range $2 \mathrm{E}-5$ to $3 \mathrm{E}-5$. The ATWS and flood sequences have a much larger spread, varying from a negligible contribution to $4 \mathrm{E}-5$ and $7 \mathrm{E}-5$, respectively. The means for the ATWS and flood sequences are about an order of magnitude lower than the means of the other three summary sequences. The plants are spread fairly uniformly throughout the range for each sequence except that the ATWS and flood sequences each have a high outlier plant.

The fractional contribution to total plant CDF also varies considerably within most of the sequences. For station blackout, the contribution varies from about 5 to $60 \%$; for transients, the contribution varies from 5 to $85 \%$; for LOCAS, the contribution varies from 10 to $55 \%$; and for floods, the contribution varies from negligible to $30 \%$. The variation for ATWS in terms of fractional contribution is much less. Excluding one outlier plant with a contribution of $20 \%$, the remaining plants have ATWS contributions of less than $10 \%$.

Figure 6 shows the ranges of CDFs for each accident class, and the percentage contributions to the overall plant CDF by accident class for the twenty BWRs. Across all the BWRs cited in this paper, SBO, $\mathrm{T}$, and DHR accident sequences are typically the dominant contributors to the CDF. Over the whole group, these three classes of accident sequences combine to represent about $82 \%$ of the total CDF, with ATWS contributing about another $10 \%$ to the CDF. The mean CDFs for SBO, T and DHR sequences are in the range of $4 E-6$ to $9 E-6$, and the mean ATWS CDF is $1 E-6$. The other classes of accident sequences (i.e., LOCA, FLD, $R$, and $V$ ) generally tend to contribute very little to the CDF ( $8 \%$ all together).

The spread in the BWR sequence results is much larger than for the PWRs. Typically, the high and low CDFs for a particular sequence vary by about three orders of magnitude. In terms of percent contribution, the three dominant sequences (SBO, T, DHR) vary from a negligible contribution to about $80-90 \%$. The variation in sequence contribution to CDF within the other sequences is much less, with ATWS varying from negligible to about $40 \%$, and the remaining sequences generally falling below $20 \%$.

The sequence results were also examined for the various plant groups described above. Generally, the differences among plant groups in mean sequence CDFs and fractional contribution to plant CDF were less than the variations observed within the individual plant groups.

The IPE Insights Program is currently investigating the reasons for the observed differences in plant CDF and sequence CDF results. Preliminary results indicate that the variations are due to multiple influences. In general, the differences in results are due to the combined effect of plant design/operational characteristics and differences in IPE modeling and assumptions. To date, no single factor has been found whose variation can explain the observed difference in sequence CDFs. 


\section{PWRs}
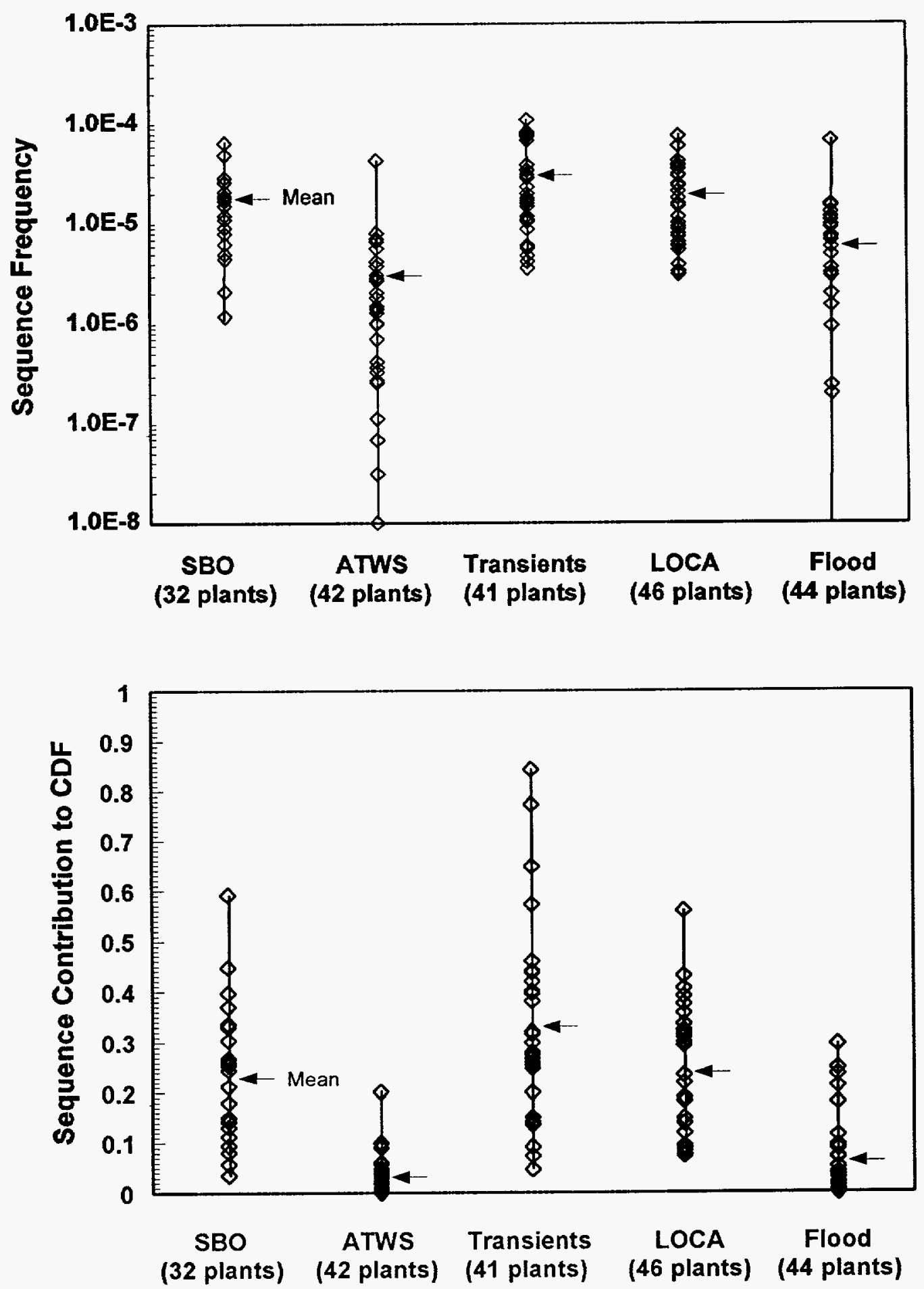

Figure 5 PWR Accident Sequence Frequencies and Contribution to Plant CDF 

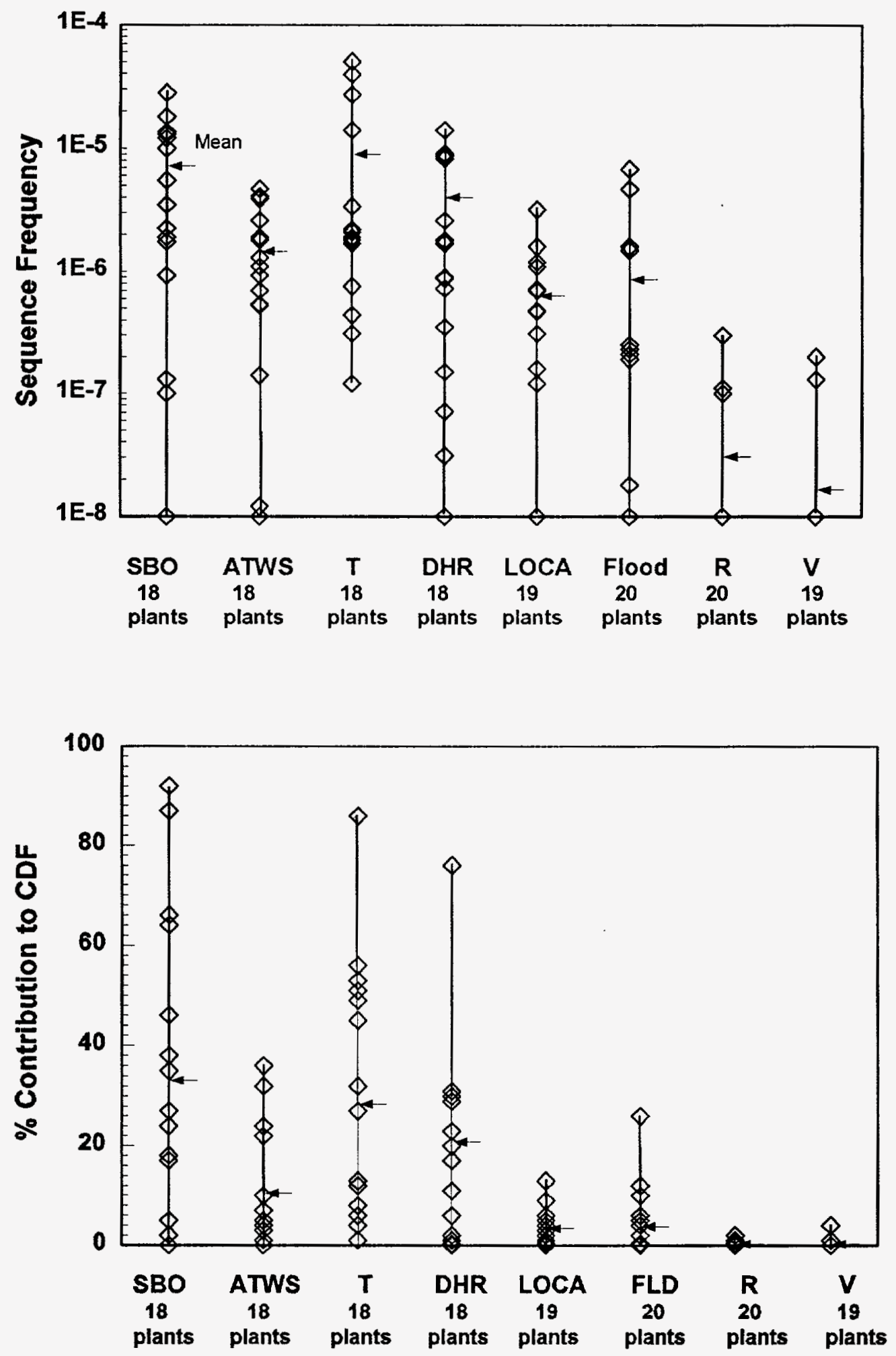

Figure 6 BWR Accident Sequence Frequencies and Contribution to Plant CDF 
Figures 7 and 8 show examples of the influence of a variable on the sequence CDF. Figure 7 shows a scatter plot of the SBO CDF for PWRs plotted against the battery life, and Figure 8 shows the ATWS CDF for BWRs plotted against the probability that the operator fails to manually initiate standby liquid control (SLC). Neither factor can account for the observed variation in sequence CDFs. This tendency is typical for all comparisons that have been made in the IPE Insights Program. In general, the variation in results is caused by a combination of factors.

\section{SUMMARY}

The IPE Insights Program has been established to gain safety perspectives from the IPE results. To date, the plant CDF, sequence CDFs and dominant contributors have been identified (to the extent possible from the IPE submittals) and categorized. On average, the PWR CDFs are larger than the BWR CDFs, but the individual plant results vary considerably. Examination of the results indicates that variations among plant results are due to a combination of actual plant design/operational features and analysis approaches.

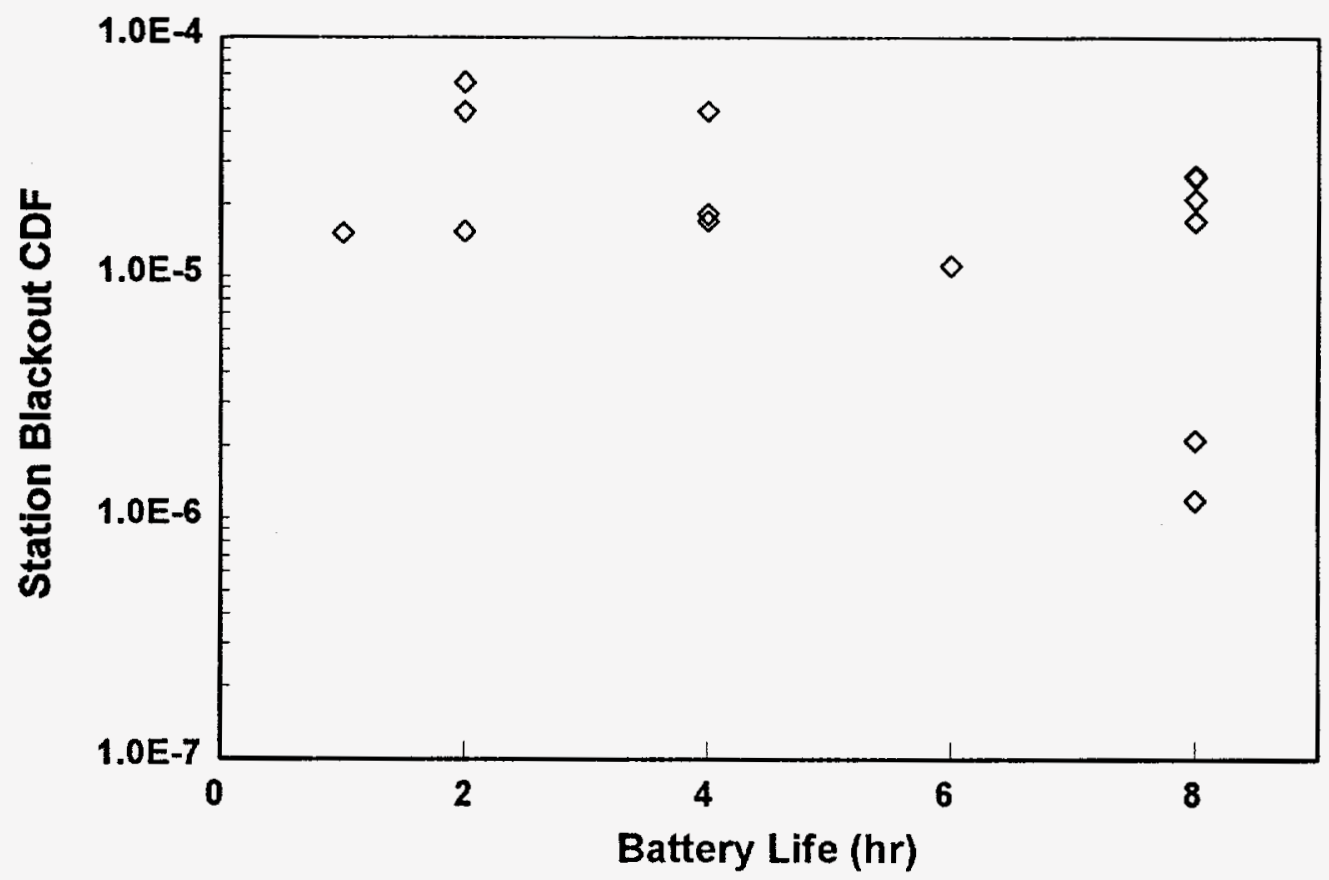

Figure 7 Dependence of PWR SBO CDF on Battery Life 


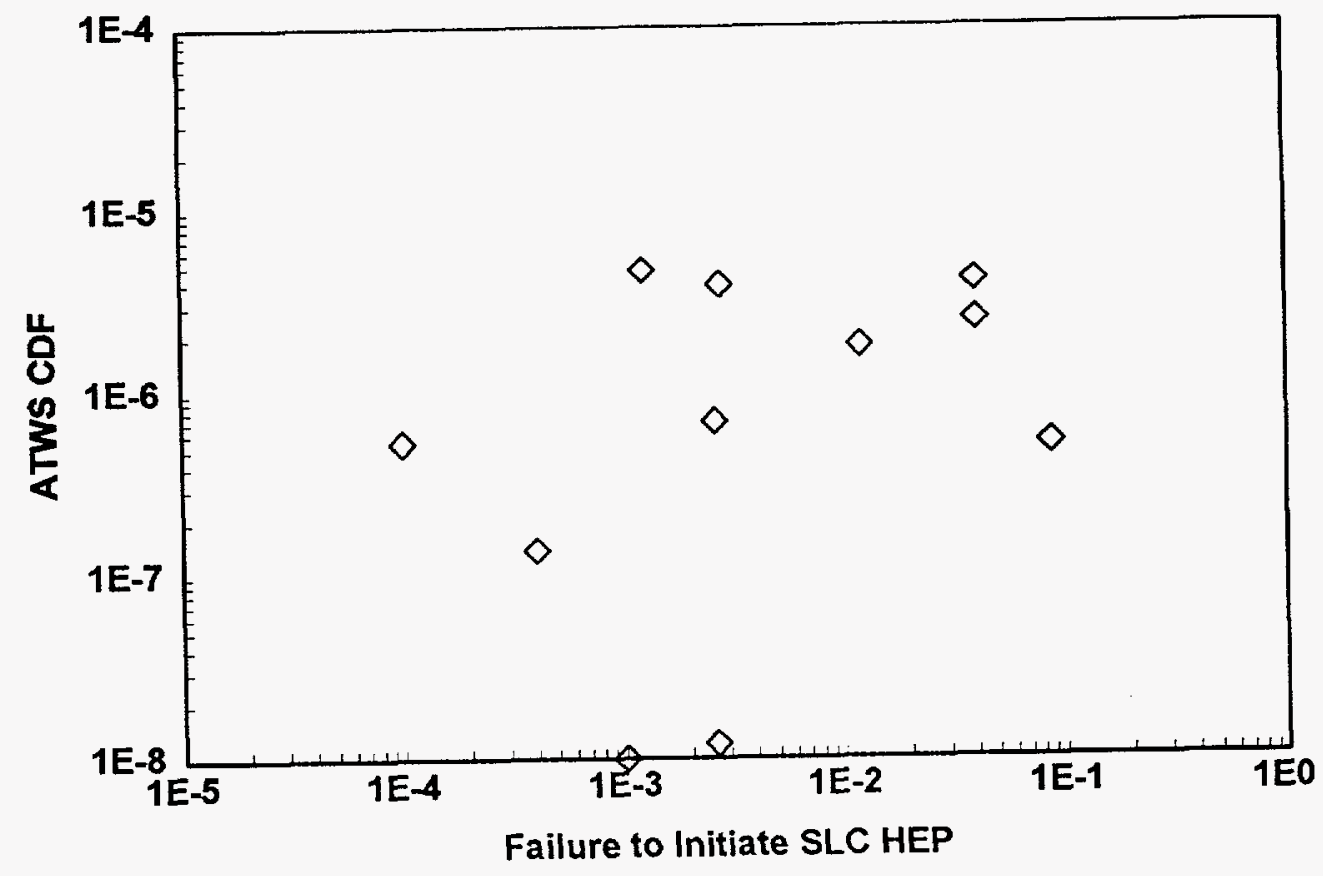

Figure 8 Comparison of BWR ATWS CDF to SLC HEP

\section{DISCLAIMER}

This report was prepared as an account of work sponsored by an agency of the United States Government. Neither the United States Government nor any agency thereof, nor any of their employees, makes any warranty, express or implied, or assumes any legal liability or responsibility for the accuracy, completeness, or usefulness of any information, apparatus, product, or process disclosed, or represents that its use would not infringe privately owned rights. Reference herein to any specific commercial product, process, or service by trade name, trademark, manufacturer, or otherwise does not necessarily constitute or imply its endorsement, recommendation, or favoring by the United States Government or any agency thereof. The views and opinions of authors expressed herein do not necessarily state or reflect those of the United States Government or any agency thereof. 